\title{
Modelling and simulation of a series wound direct current motor using ANSYS
}

\author{
István Kovács ${ }^{1, *}$, Kornél Sarvajcz ${ }^{1}$ \\ ${ }^{1}$ Mechatronics Department, Faculty of Engineering, University of Debrecen, Hungary
}

\begin{abstract}
In this paper we will discuss the process of making the model of a series wound DC motor and performing simulation and analysis using the ANSYS products. The geometry model was done in RMXprt, and the electromagnetics simulation in MAXWELL. Using the data acquired from those analyses a thermodynamical simulation was also done on the geometric model.
\end{abstract}

\section{Introduction}

The goal of the project was making a geometric model and performing electromagnetics simulation on an electric motor using ANSYS. The electric motor in question was used as a traction motor in an electric competition vehicle built by the students of the Engineering Faculty of University of Debrecen. The first steps of the job were learning how the software works, doing research on the subject of direct current (DC) motors. Once that has been done, we can model the motor's geometry in RMXprt, and do analysis in the MAXWELL electromagnetics module. The ANSYS products provide great solutions for mechanical, electrical and fluid dynamics problems using finite element methods.

\section{Prologue}

\subsection{A short introduction to electric machines}

Working principle of electric machines

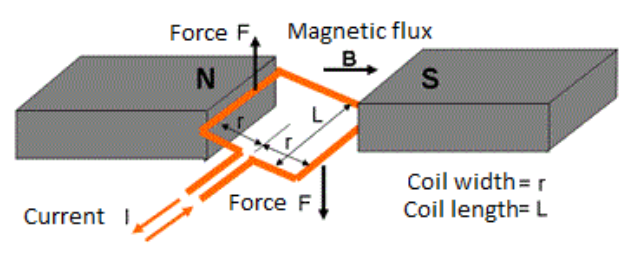

Fig. 1. Basic working principle of electric machines.

The basic working principle of electric motors is the electromagnetic induction. Around every conductor, in which current flows through, there will be a magnetic field created. The change in magnetic field will produce a change in the electric field. The force that acts upon the conductor in the magnetic field is called Lorentz-Force [2]. This force creates the moving torque in the electric motor, that we can use for different purposes, like lifting loads or propelling a vehicle [1] (Fig. 1).

\section{Properties of the modelled electric motor}

The first step towards the goal of the project was the disassembly of the motor. We had to take measurements on the different parts, because a detailed datasheet was not available for the product. The motor is a series wound direct current motor, and it was used on a voltage of 12 [V] powered by batteries, propelling the electric vehicle by a chain drive.

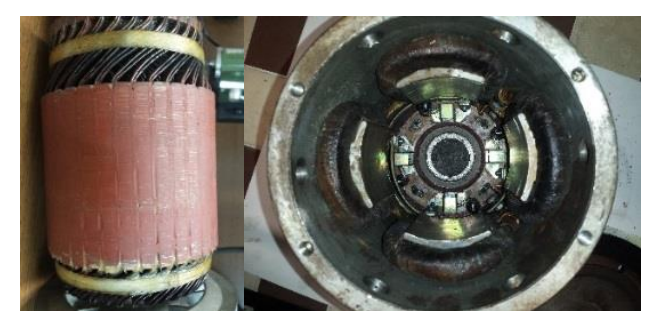

Fig. 2. The rotor (left) and stator (right) of the electric motor.

The data plate on the stator housing provided some nominal or peak values of the electric motor, the model number is ZC4-48C, the nominal current is 103 [A], nominal voltage is $48[\mathrm{~V}]$, nominal speed 1200 [rpm] (with a maximum of 4000 [rpm]) and nominal torque of $14,7[\mathrm{Nm}]$. The number of poles in this model is 4 , the carbon brushes are placed according to the placement of the poles, there are 4 brushes divided by $90^{\circ}$ from each other, under the poles. The conductor used for the stator coils has 8 strands of wire, with a diameter of 1,75 [mm] each, and the coils on each pole consist of 1,5 turns. The rotor has 36 slots, in which the rotor coils are placed with wave winding pattern [3]. The conductor used for this winding consist of 2 strands of rectangular wire with 0,8 [mm] height and $4[\mathrm{~mm}]$ width. These are the most important values that describe the winding on the stator and the rotor

\footnotetext{
* Corresponding author: k.ist96@mailbox.unideb.hu
} 


\section{Creating the model}

One of ANSYS's electrical modules is the RMXprt, it can be used for setting up geometry of electric machines. Also it gives a quick performance and operating overview of the electric machine with a simulation.

The software uses prebuilt templates for different electric machine designs and these can be adjusted with the measured (or calculated) values of the dimensions and winding properties.

In the software window (Fig. 3.) on the left hand side there is a project tree containing every part of the geometry. Here are the settings for the type of the electric machine (alternating or direct current, and the different designs of each type). Also the operation of the machine can be set, either motor or generator simulation can be done. Each part of the geometry can be opened and under the „Properties" window the dimensions or other properties of the part can be set to the desired values. Based on these values and parameters the software creates a $2 \mathrm{D}$ axial cross section of the motor. Here the winding and the coils are not shown, however they are included in the calculations. The most critical properties for an accurate operating model are the windings on the stator and rotor, and the poles of the stator.

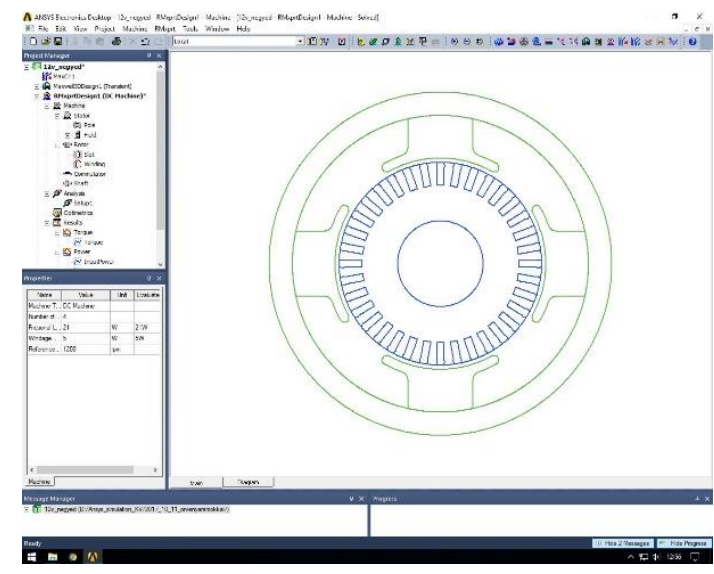

Fig. 3. 2D model of the electric motor in RMXprt.

At the analysis settings we can set the load of the motor to the desired type, these can be constant power/speed/torque, linear torque or fan load (where we increase the torque proportional to the speed). During the RMXprt analyses we used the fan load setting. We can set the nominal values of the electric machine in the properties window [4].

An important note on these simulations is, that the RMXprt module performs only static analysis. The different parameters are not displayed in function of the time (as in a transient analysis), instead they are displayed in function of a different parameter.

\section{Evaluation of the results}

According to the results of the RMXprt simulation, the operation of the motor is close to the nominal values. The current flowing through the coils is 108 [A] at 48 [V] voltage. However the produced torque does not meet the nominal $14,7[\mathrm{Nm}]$ in fan load operation, these results can be improved with further simulations in the MAXWELL module.

\section{Modelling in MAXWELL3D}

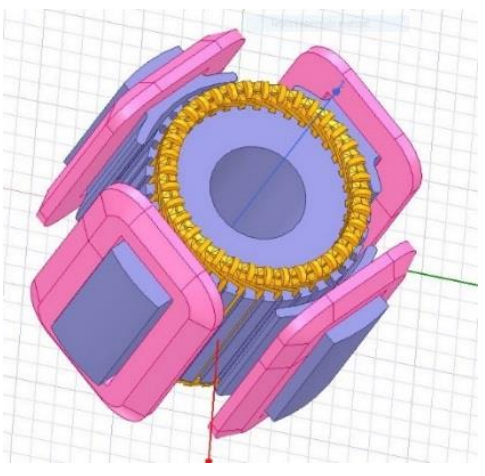

Fig. 4. 3D model of the electric motor in MAXWELL (without the outer frame).

The next part of the analysis was done in the MAXWELL module, here we can observe the operation of the motor considering different losses, and also the change of electromagnetic fields during the operation. Using the 2D model created by the RMXprt module, the MAXWELL module can extend the cross section to a 3D model (Fig. 4.). The MAXWELL module can operate with only a segment of the geometry to decrease the resources needed for the calculations. The MAXWELL module also has 3D drawing tools, so we can set up the whole geometry in this module (using primitive shapes), although it would require more time and effort.

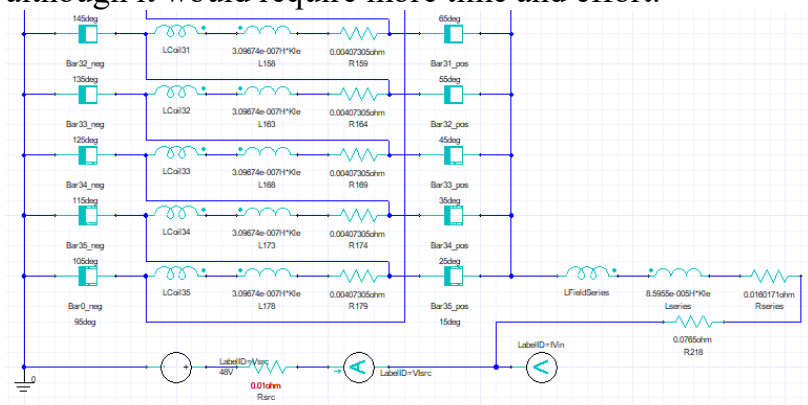

Fig. 5. A section of the windings' circuit diagram in MAXWELL

After we export the geometry model, the software creates the corresponding electrical circuit from a template, this comes with an advantage that different elements of the geometry become automatically connected to each other. We can also edit the circuit diagram and set the values on the different components.

If we want to do thermodynamical analysis, we have to adjust the thermal coefficients of the conductors. By default the simulation will not calculate with the thermal coefficient. The resistance of the conductors changes with the temperature and this can affect the performance of the motor. Also this result can be the base of a thermodynamical simulation 


$$
\sigma^{\prime}=\sigma \frac{1}{1+0.0039 *(T-22)}
$$

The 1 . equation defines the relation between the temperature and the conductivity. Unless we allow the addition of the „Thermal Modifiers", the software won't compute thermal losses. Aside from thermal losses, we can compute other type of losses - eddy currents and core losses.

For the simulations we set the duration to $2[\mathrm{~s}]$ and the time step at which the calculations occur to $60[\mu \mathrm{s}]$.. Fig. 6. shows the current-time graph. The red coloured line means the current on one coil of the rotor winding, and the purple line on the field winding. The peak current on the field winding is 222.21 [A], and 55.63 [A] on the rotor coil, this occurs at the start of the motor. These values drop top 103.36 [A] and 22.26 [A] respectively after $2[\mathrm{~s}]$ of running time.

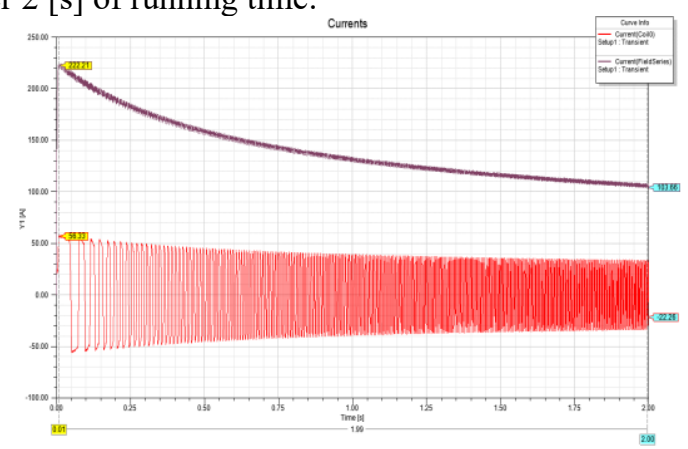

Fig. 6. Current-time graph of the stator (purple) and rotor (red) windings

The following Fig. 7. shows the torque-time graph. At the start of rotation the motor produces $14.84[\mathrm{Nm}]$ torque, which diminishes to $3.54[\mathrm{Nm}]$ after $2[\mathrm{~s}]$.

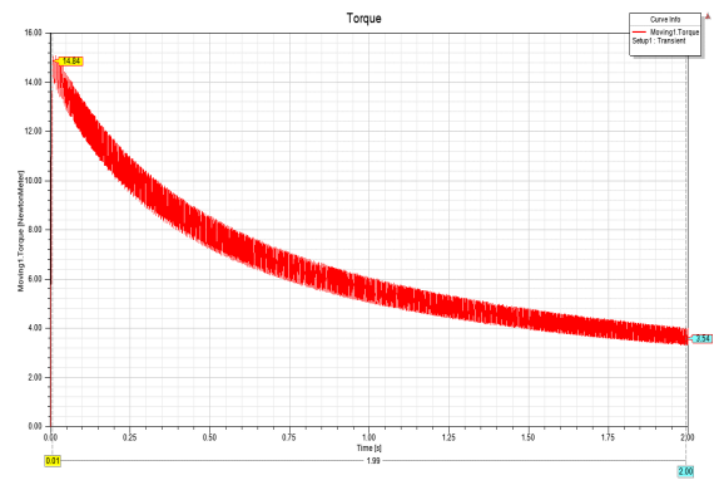

Fig. 7. Torque-time graph of the electric motor

Fig. 8. shows the speed-time graph of the motor, which links the torque and current graphs. After 2 [s] the motor reaches 4000 [rpm] which is it's highest rated speed. The results show the relation between current and torque, which is proportional, and the current and torque values are inversely proportional to the speed. This relation is fitting for a series wound DC motor.

Creating graphs is not the only way we can display the results of the analysis. We can create animations that show how the electromagnetic field occurs and changes during the operation of the motor. The save of the data corresponding to these fields does not happen by default.

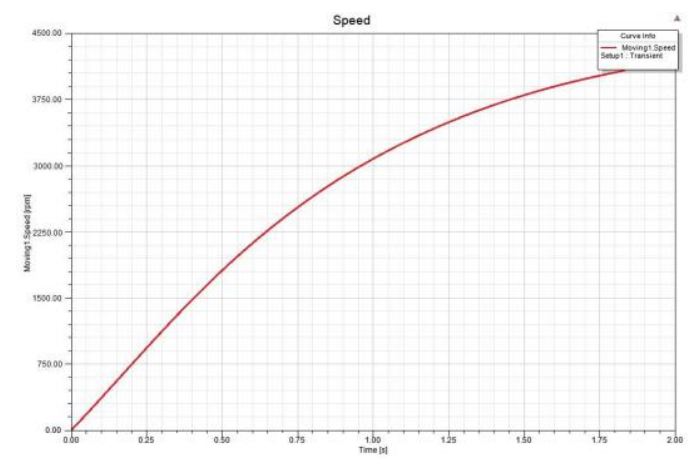

Fig. 8. Speed-time graph of the electric motor

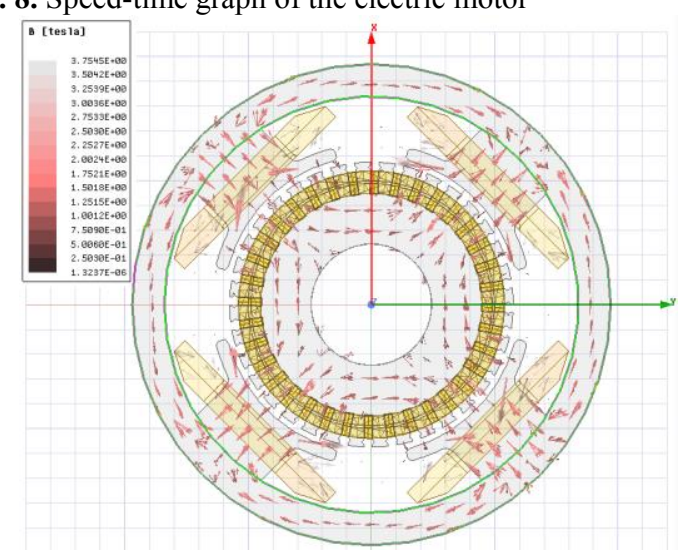

Fig. 9. Magnetic flux density, B vector shown in the motor

Fig. 9. shows the flux density measured in [tesla], also called as B vector. This gives the amount of magnetic induction lines crossing a given surface. In most cases we describe the strength of magnetic field with the flux density, because we can measure the magnetic flux easier than the intensity of the magnetic field. Also the direction of the vectors show the direction of the flux lines and the poles of the field. We can see how the magnetic lines go from magnetic pole to pole, according to the poles of the stator where the field windings are placed.

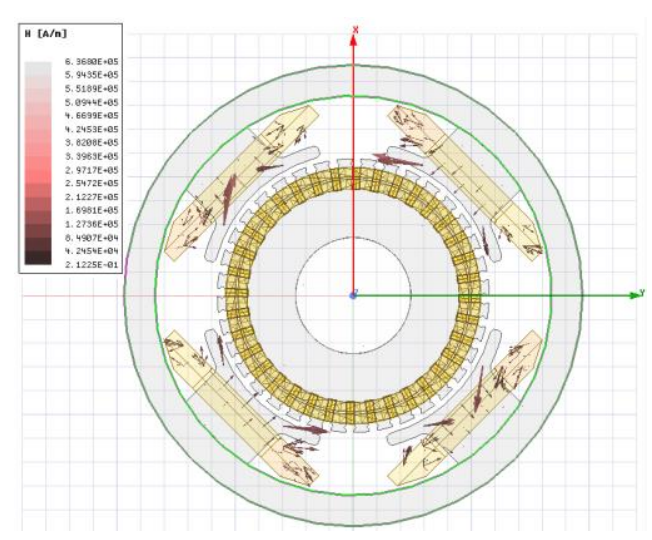

Fig. 10. Magnetic field strength, $H$ vector shown in the motor

Fig. 10. shows the intensity of the magnetic field, measured in $[\mathrm{A} / \mathrm{m}]$, also called $\mathrm{H}$ vector. This quantity can be related to the direction of the current. It shows the direction and amount of force the magnetic field exerts 
on a magnetic material. The highest value of field intensity can be found on the poles of the stator.

Fig. 11. shows the current density in the conductors, also known as $\mathrm{J}$ vector, measured in $\left[\mathrm{A} / \mathrm{m}^{2}\right]$. This shows the current flowing through a given cross section of conductors. The figure shows the direction of the current during the commutation of rotor coils.

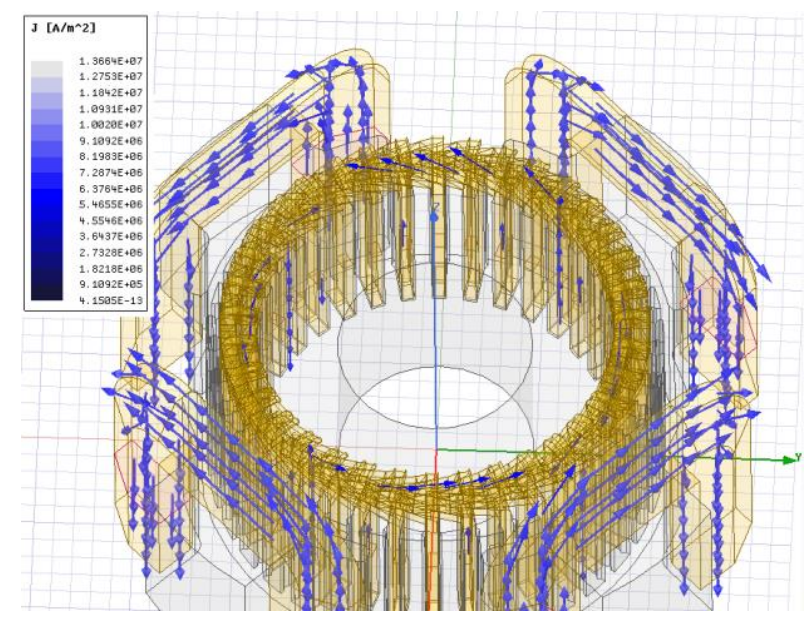

Fig. 11. Current density of conductors, J vector shown in the motor

\section{Thermodinamics analysis}

To perform a thermodynamics simulation, we have to use the Workbench. We can connect the MAXWELL module with the thermodynamical modules of ANSYS Mechanical. We can conduct both transient and steadystate analysis, we used both simulations.

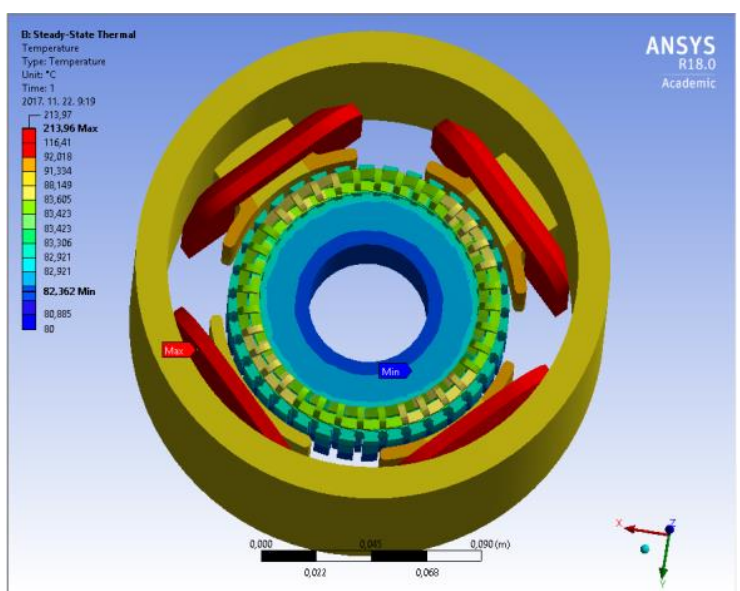

Fig. 12. Results of a steady-state thermal analysis

Fig. 12. shows the steady-state result of the analysis. In this case we take the greatest thermal load and assume that it affects the geometry during the whole simulation. This is the reason why the elements reach a much higher temperature than in the transient analysis (and the real operation of the motor). The peak temperature is 213.96 $\left[{ }^{\circ} \mathrm{C}\right]$, which is too high for the motor to operate normally, it would cause damage to the winding.

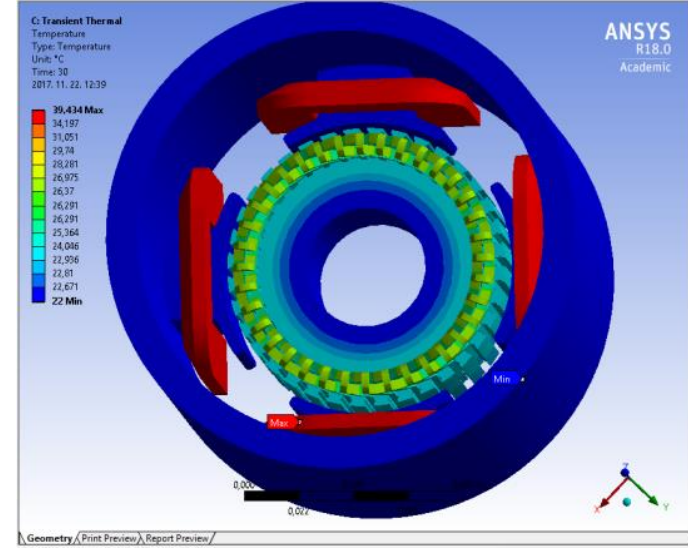

Fig. 13. Results of a transient thermal analysis

Fig. 13. shows the transient result of the simulation, which represents the real operation. The peak temperature is $39.434\left[{ }^{\circ} \mathrm{C}\right]$ after 30 [s]. According to the insulation class $\mathrm{F}$ on the nameplate of the motor, the maximum internal temperature without causing any damage can go up to $155\left[{ }^{\circ} \mathrm{C}\right]$. This means that this operation would not cause damage to the motor.

\section{Summary}

\subsection{Evaluation of the project}

We created a 2D and 3D model. Performed transient simulations using MAXWELL. The results were evaluated in graph and animation forms. Based upon the results a thermodynamical simulation was also done. These results can be made more accurate with the involvement of further modules and the use of smaller time steps in the simulations. Using the results of the thermodynamics analysis, we can create a fluid dynamics analysis, which can be linked back to the thermal module to produce the airflow created by the heat to get better results. These steps can be repeated to get more accurate results each time. Also we can use the MAXWELL module to optimize the parts of the electric motor.

\section{Acknowledgement}

The work/publication is supported by the EFOP-3.6.116-2016-00022 project. The project is co-financed by the European Union and the European Social Fund.

\section{References}

1. Chapman, Stephen J. Electrical Machinery Fundamentals. $4^{\text {th }}$ Ed. (2005)

2. Simonyi Károly, The history of physics, A fizika kultúrtörténete, $2^{\text {nd }} \mathrm{Ed}$. (1981).

3. Pálfi Zoltán, Electric drives, Villamos hajtások, 1978.

4. Páczelt István, Szabó Tamás, Baksa Attila Fundamentals of the finite element method, A végeselem-módszer alapja (lecture) 